\title{
EFFECT OF SLOPE ANGLE ON ENERGY PERFORMANCE OF GROUND-INTEGRATED BUILDINGS ON SLOPE TERRAIN
}

\author{
M. DE CASTRO \& M.B. GADI \\ Department of Architecture and Built Environment, The University of Nottingham, United Kingdom.
}

\begin{abstract}
The noticeable rise in urban development and topography factors across Europe has resulted in a visible increase in the number of residential buildings being constructed in hillside areas. Several studies about ground-integrated architecture have proved that buildings can benefit from ground thermal potential, in order to reduce or eliminate the heating and cooling needs. However, only a small number of published articles tackle the potential of ground-integrated buildings on sloped terrains. The purpose of this paper is to explore the ground thermal potential of sloped terrains in temperate climates, through parametric studies using EnergyPlus as the energy modelling software. This paper looks at two main questions: firstly, how buildings are affected by terrain inclination and, secondly, which types of slope building designs are more thermally efficient, particularly the case of spilt level, amended section and cascade or step-hill designs.

Keywords: energy saving potential, energy-efficiency, energyplus, ground thermal simulation, slopebuilding designs, slope-integrated architecture, temperate climate.
\end{abstract}

\section{INTRODUCTION}

Far from being a new way to control building thermal comfort, slope settlements are one of the earliest settlement configurations, having been used since the Neolithic period $[1,2]$. Generally, these configurations provided natural advantages due to their use of south face oriented terrains that attenuate local climactic conditions [1]. Housing on slopes can gain a large number of benefits compared with those constructed on a flat site. Examining the advantages and disadvantages of flat and slope land constructions, Golany [3], concluded that ground-integrated constructions in slope hills are better than those built on flat land, it reduces the claustrophobic feelings, minimise flood's impact, provides better ventilation, can provide better light access and achieve the best thermal performance in a moderate climate. Other benefits of sloped urban sites, as opposed to low-flat sites, are the better views and the reduction of health risks, due to better air ventilation reducing air pollution $[4,5]$.

The energy consumption of sloped land settlements is lower than flat land settlements. Sites on flat land or in the valleys are subject to higher air temperature amplitudes and, therefore, the heating and cooling demands are higher [5]. A flat land settlement in a hot, dry climate consumes more 50\% energy than a south-facing sloped settlement [2]. Lee and Shon [6] compared the thermal performance of a sloped ground-integrated housing and an above-ground flat site house in South Korea. According to the authors, the slope-integrated building achieved better thermal behaviour and provided better thermal comfort throughout the whole year. Recently, Benardos et al. [7] compared the thermal performance and 
construction costs of one slope-integrated and one above ground residential design in the Kea Island (Greece). The results of this study show that the slope-integrated design is better than the above ground design, as it provided cooling savings of $25 \%$ and total energy demand savings of $42 \%$ over the course of the study. The construction cost analysis indicates that the above-ground design is only $8 \%$ cheaper to construct than the slope-integrated design, and the cost difference can be reduced further if maintenance as well as operational cost are taken into account.

Slope-integrated construction contributes to efficient land use [6, 8]. Underground buildings integrated into flat land sites require higher percentages of land than comparable slope-integrated buildings [4]. On average flat land settlements occupy double the area of a slope settlement with the same characteristics [2]. In addition, due to safety concerns, the area above ground-integrated buildings constructed on flat land cannot be used for agriculture, resulting in a waste of land. Simpson and Purdy [9] point to an increasing tendency to build on slope terrains in the UK, which was linked to the increasing scarcity of flat land and to a rising concern about preserving agricultural land. Both these issues are global, as the shortage of flat construction land is an ongoing problem, and the rapid urban development of past decades had led to dramatic increases in land prices and to the claiming of farming land $[4,8,10,11]$. To continue the practice of building in flat land could lead, in the near future, to food shortages due to the waste of good agriculture land. Since flat land tends to have the richest soil, ideal for agriculture [12], slope-integrated buildings are able to maximize the use of land generally not suitable for agriculture proposes [4].

\section{SLOPE SITE DESIGN ADAPTATIONS}

Ground-integrated buildings are considered ideal for sharply inclined sites [6, 12, 13]. However, the benefits of constructing housing on slopes are not always considered and normally ignored. As Simpson and Purdy point out, slopes appear "to be regarded as a nuisance to be overcome rather than as an opportunity to be exploited" [9, p. 9]. Regarding housing design, the authors identify six methods of adapting a building to a slope site or designing a building to accommodate the slope. As listed in Table 1, these methods are extra masonry, cut-and-fill, building on posts, amended section, split level and cascade or step-hill.

Three of these methods are based on adapting (in either a simple or complex way) a building designed for a flat site to fit a slope site. Site adaptations can consist of: adding extra masonry for small adjustments of building walls on the lower side of the site, cut-and-fill that level the site in a flat area or by erecting houses on posts, so that the building is suspended and, therefore, detached from the ground.

In the case of amended section, split level and cascade or step-hill, the building is designed from the start to take site slope into consideration. The amended section uses several floor levels that normally can have different outside access depending on the precise configuration of the terrain. With the split level the building floors are organised in several levels, which can be based on half storey variations of floor levels. The cascade or step-hill generates an off-set that is linked with the steepness of the slope. With this latter design it is possible to create horizontal and or vertical subdivision, forming several individual units.

\section{RESEARCH METHOD}

In this study, the authors compared four models with slope building designs and a model without slope design. The slope building designs used in this study are based on three types of slope designs that accommodate the slope, namely the spilt level, amends section and 
Table 1: Types of house design on slope sites based on Simpson and Purdy.

Adaptation of the site

cascade or step-hill designs outlined above. Examining the efficiency of these models, this paper addresses two main questions: firstly, how these designs are affected by site slope degree and, secondly, which slope building designs are more thermally efficient. The models were simulated using EnergyPlus version 8.1. The simulation settings and input data are the following ones:

- Simulation Method: this study used the Slab and Basement auxiliary programs. From the three recommended methods $[14,15]$ applied during the models' first run the initial one was chosen for this study, which set the monthly average ground temperature to $18^{\circ} \mathrm{C}$.

- Location/Weather File: the location selected for this study is Lisbon and the weather file used in this study is PRT_Lisboa.085360_INETI.epw distributed by EnergyPlus, and produced with public data published by the Instituto de Meteorologia based in Lisbon, which are then combined with data from the Instituto Nacional de Engenharia, and the Tecnologia e Inovação data and made available to the DOE.

- Internal Gains: no internal gains were used.

- Ventilation: no ventilation was used.

- Infiltration: no infiltration was used.

- HVAC: the eating SetPoint is $20^{\circ} \mathrm{C}$ and cooling SetPoint is $26^{\circ} \mathrm{C}$.

- Openings: no openings were used. 
- Materials: to prevent differences in results caused by complex material inputs and amplified by the impact of ground contact, all models in this study use a single construction material of $20 \mathrm{~cm}$ concrete (Table 2).

- Seasonal data: it is assumed that winter period corresponds to January, February and March; the spring period combines April, May and June; the summer season is formed by July, August and September; the autumn period is formed in October, November and December.

\section{MODELS DETAILS AND LEVELS OF SLOPE INTEGRATION}

The five models used in this study share the same total area of $168 \mathrm{~m}^{2}$, equal number of zones (3) and unit area $\left(56 \mathrm{~m}^{2}\right)$. The designs used in this study are a basic single level Model SlopeBD 01, a split level Model SlopeBD 02, a cascade with independent units Model SlopeBD 03, a cascade with connected units Model SlopeBD 04, and lastly an amended section structure Model SlopeBD 05. The models' dimensions, slope integration and correspondent name are listed in Table 3.

This study uses slope integration levels from null $\left(0^{\circ}\right)$ up to $50^{\circ}$, with $10^{\circ}$ intervals between each level, as illustrated in Table 4. The maximum wall depth with ground contact is $8 \mathrm{~m}$ according to each model's design, as well as the type of slope. All models in the simulation assume that roofs have full sun and wind exposure.

Table 2: Models' material properties.

\begin{tabular}{llll}
\hline $\begin{array}{l}\text { Conductivity } \\
\left(\mathrm{W} / \mathrm{m}^{\circ} \mathrm{C}\right)\end{array}$ & Density $\left(\mathrm{kg} / \mathrm{m}^{3}\right)$ & $\begin{array}{l}\text { Specific heat } \\
\left(\mathrm{J} / \mathrm{kg} .{ }^{\circ} \mathrm{C}\right)\end{array}$ & $\begin{array}{l}\text { Thermal resist. } \\
\left(\mathrm{m}^{2}{ }^{\circ} \mathrm{C} / \mathrm{W}\right)\end{array}$ \\
\hline 0.51 & 1,400 & 1,000 & $\mathrm{R}=0.2 / 0.51=0.392$ \\
\hline
\end{tabular}

Table 3: Models details - slope building design study.

Cascade (Step-hill); linked


Table 4: Level of slope integration - simplified representation.

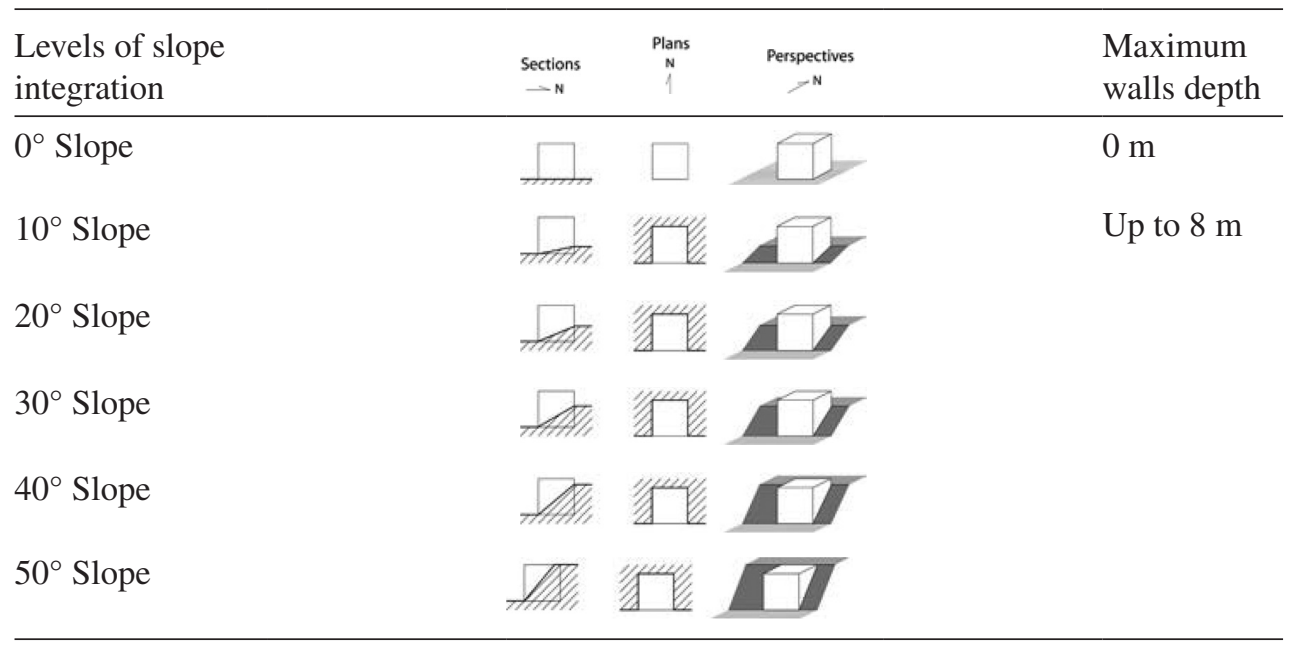

\section{RESULTS ANALYSIS}

\subsection{Annual results}

Regarding the slope integration effect, observable in Fig. 1, for all models it was found that the total annual loads decreases according to the slope, and therefore the higher the slope is, the lower the models' annual load. Consequently, the least efficient thermal performances are found with the null slope and the most efficient are achieved with the highest gradient, which corresponds to a $50^{\circ}$ slope. However, it is visible that between a $30^{\circ}$, a $40^{\circ}$ and a $50^{\circ}$ slope the results gap is almost negligible. For this reason the use of slopes higher than $30^{\circ}$ should be considered before other factors, since there is not any noticeable advantage to using the highest slopes of $40^{\circ}$ or $50^{\circ}$.

The annual slope integration effect pattern is reiterated in the results provided in Table 5, which provides a summary of all models' results by using a performance scale from best (1) to worst (6). Table 6 shows the annual savings percentage for each model according to the slope level.

Both Tables 5 and 6 indicate that slope integration is able to improve the thermal performance of the models, and that the higher the slope the better the model's result. The annual average savings can be up to $24.08 \%$ with a $50^{\circ}$ slope. From a null slope to a $30^{\circ}$ slope for each $10^{\circ}$ the average savings difference is around $6.5 \%$. These values drop to $3.2 \%$ for $30^{\circ}$ to $40^{\circ}$ slope, and to $1.42 \%$ for $40^{\circ}$ to $50^{\circ}$ slope.

The design effects produced by slope building designs can be observed in Table 7, which provides each model's annual savings value, compared with the level of slope integration. The amended section design, which corresponds to Model SlopeBD 05, has the best performance with an average annual savings of $18.54 \%$. These values are followed by the single level Model SlopeBD 01, which reaches 15.74\%, Model SlopeBD 04 with a cascade with connected units, which achieves 13.75\%, the spit level Model SlopeBD 02 that produce $10.67 \%$, and lastly the cascade design with independent unit Model SlopeBD 03, which achieves the worst results of $0.45 \%$. However, it should be noted that models' performance 


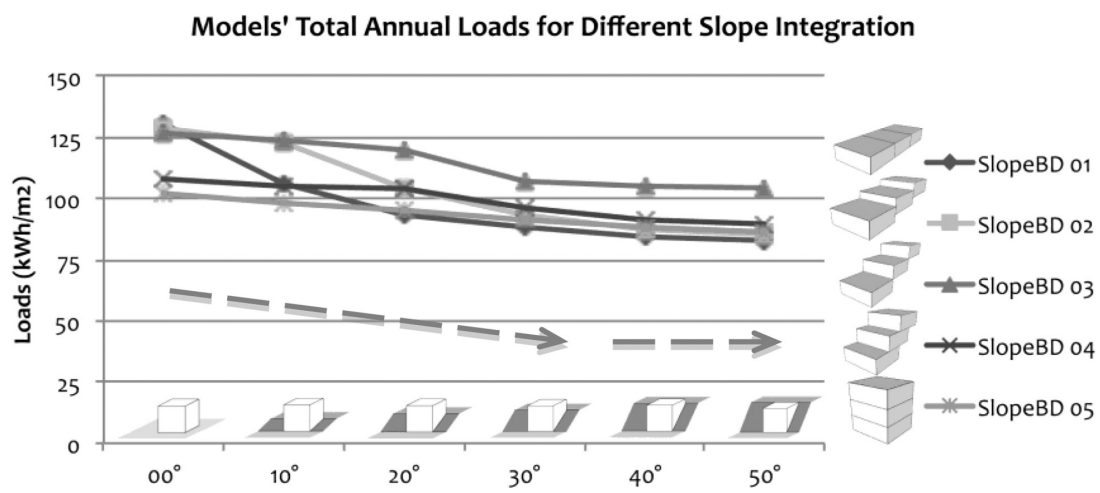

Figure 1: Slope effect on slope building design models' total annual load.

Table 5: Annual slope effect - models' thermal performance according with slope integration.

\begin{tabular}{|c|c|c|c|c|c|}
\hline $0^{\circ}$ Slope & $10^{\circ}$ Slope & $20^{\circ}$ Slope & $30^{\circ}$ Slope & $40^{\circ}$ Slope & $50^{\circ}$ Slope \\
\hline 6 & 5 & 4 & 3 & 2 & 1 \\
\hline \multicolumn{6}{|c|}{$\leftarrow$ Scale* 1 to $6 \rightarrow$} \\
\hline
\end{tabular}

* Perfromance Scale 1 to $6(1=$ Best performance $\& 6=$ Worst performance $)$;

Table 6: Slope effect - annual savings (\%) per model according to slope integration.

\begin{tabular}{lcccccc}
\hline & \multicolumn{7}{c}{ Levels of slope integration } \\
\cline { 2 - 7 } & 0.00 & 18.81 & 28.03 & 32.43 & 35.09 & $\mathbf{3 6 . 3 5}$ \\
Models & 0.00 & 4.65 & 19.27 & 27.58 & 32.26 & $\mathbf{3 3 . 5 3}$ \\
\hline SlopeBD 01 & 0.00 & 1.93 & 5.23 & 15.81 & 17.22 & $\mathbf{1 7 . 6 3}$ \\
SlopeBD 02 & 0.00 & 2.22 & 3.85 & 11.00 & 15.22 & $\mathbf{1 6 . 9 7}$ \\
SlopeBD 03 & 0.00 & 4.17 & 7.07 & 10.47 & 13.50 & $\mathbf{1 5 . 9 3}$ \\
SlopeBD 04 & & & & & & \\
SlopeBD 05 & 0.00 & 6.36 & 12.69 & 19.46 & 22.66 & $\mathbf{2 4 . 0 8}$ \\
$\begin{array}{l}\text { Average savings \% per } \\
\text { Slope integ. } \\
\text { Average increase range \% }\end{array}$ & 0.00 & $\mathbf{6 . 3 6}$ & $\mathbf{6 . 3 3}$ & $\mathbf{6 . 7 7}$ & 3.2 & 1.42 \\
\hline
\end{tabular}


Table 7: Design effect - models' annual savings (\%) per slope integration and models overall results.

\begin{tabular}{|c|c|c|c|c|c|c|c|c|c|}
\hline \multirow[b]{2}{*}{ Models } & \multicolumn{6}{|c|}{ Levels of slope integration } & \multicolumn{2}{|c|}{ Overall results } & \\
\hline & $\square$ & $\begin{array}{l}10^{\circ} \\
\square\end{array}$ & $\begin{array}{l}20^{\circ} \\
\square=\end{array}$ & $\begin{array}{l}30^{\circ} \\
\square\end{array}$ & $\begin{array}{l}40^{\circ} \\
\square\end{array}$ & $\begin{array}{l}50^{\circ} \\
\square\end{array}$ & $\begin{array}{l}\text { Aver. } \\
\text { savings }\end{array}$ & Perfor.** & $\begin{array}{l}\frac{0}{\tilde{J}} \\
\tilde{H}\end{array}$ \\
\hline SlopeBD 01 & 0.00 & $14.92 * \mathrm{~s}$ & 21.96 & $\mathbf{1 7 . 5 2}$ & 19.42 & 20.59 & 15.74 & $=2$ & \\
\hline SlopeB D 02 & 1.27 & 1.36 & $13.58 * \mathrm{~s}$ & 12.72 & $16.97 * \mathrm{~s}$ & $18.12 * \mathrm{~s}$ & 10.67 & $=4$ & \\
\hline SlopeBD 03 & 2.69 & 0.00 & 0.00 & 0.00 & 0.00 & 0.00 & 0.45 & $=5$ & $\begin{array}{l}1 \\
n \\
\varrho\end{array}$ \\
\hline SlopeBD 04 & 17.10 & $15.05 * \mathrm{~s}$ & $13.57 * \mathrm{~s}$ & 9.93 & 12.75 & 14.12 & 13.75 & $=3$ & $\downarrow$ \\
\hline SlopeBD 05 & 21.51 & 21.18 & 20.92 & 14.23 & $15.72 * \mathrm{~s}$ & s $17.68 * s$ & 18.54 & $=1$ & \\
\hline
\end{tabular}

* Average annual savings \% per model; ** Performance Scale 1 to 5 ( 1 = Best performace $\& 5=$ Worst performance); ${ }^{* s}$ Equal or similar results.

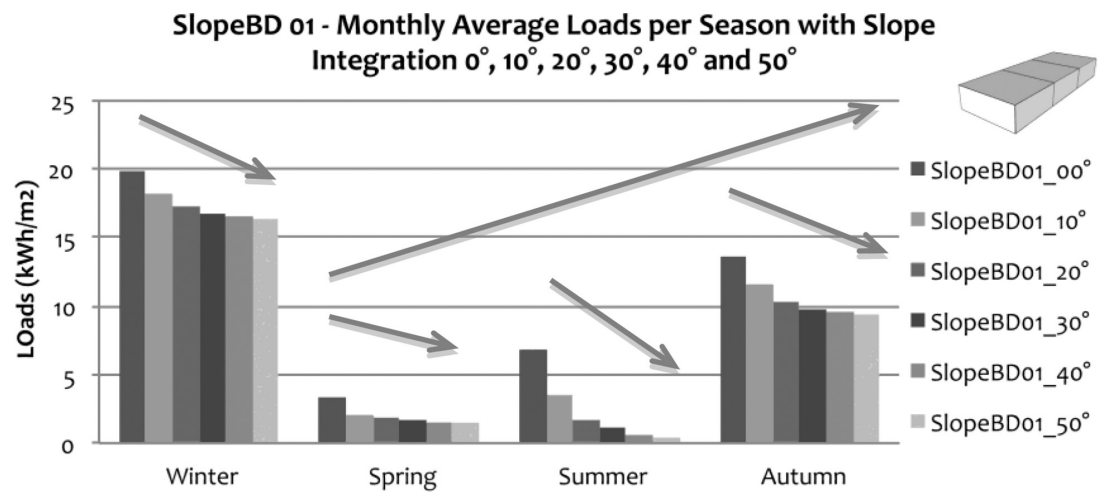

Figure 2: Slope effect - Model' SlopeBD 01average seasonal results.

pattern is different for a null slope. In this case, all models with slope building design have a greater exterior surface with direct ground contact than the single level Model SlopeBD 01, and therefore the models with slope building designs produce better results that the single level model without slope design.

\subsection{Seasonal results}

Looking at the seasonal results produced by Model SlopeBD 01 (Fig. 2), the main pattern for all seasons is that as the steepness of the slope increases the better are the models' results become. It should be pointed out that the greatest results are found in the $0^{\circ}$ to $30^{\circ}$ range of 
Table 8: Season slope effect - models season results according to slope integration.

\begin{tabular}{l}
\multicolumn{7}{c}{ Levels of slope integration } \\
\cline { 2 - 7 } \\
Season and models
\end{tabular}

* Performance Scale 1 to $6(1=$ Best performance $\& 6=$ Worst performance $)$;*Equal or very similar results

slopes. The results differences between $30^{\circ}$ slopes and $50^{\circ}$ slopes are narrow in all seasons, with almost identical results during winter and spring. This pattern is found in the performance of most models and is displayed in Table 8.

The performance summary provided in Table 8 shows that models' results improve with slope increase for slopes from $0^{\circ}$ to $30^{\circ}$. However, during spring, autumn, and winter each model produces a distinct pattern with $30^{\circ}$ to $50^{\circ}$ slopes and, once more, the models' results are similar. It should be emphasised that during these seasons, most models' results difference is minimal and consequently the thermal advantages of using steeper slopes of $40^{\circ}$ or $50^{\circ}$ are reduced. 
Table 9: Models's design effect - thermal performance according with seasonal loads.

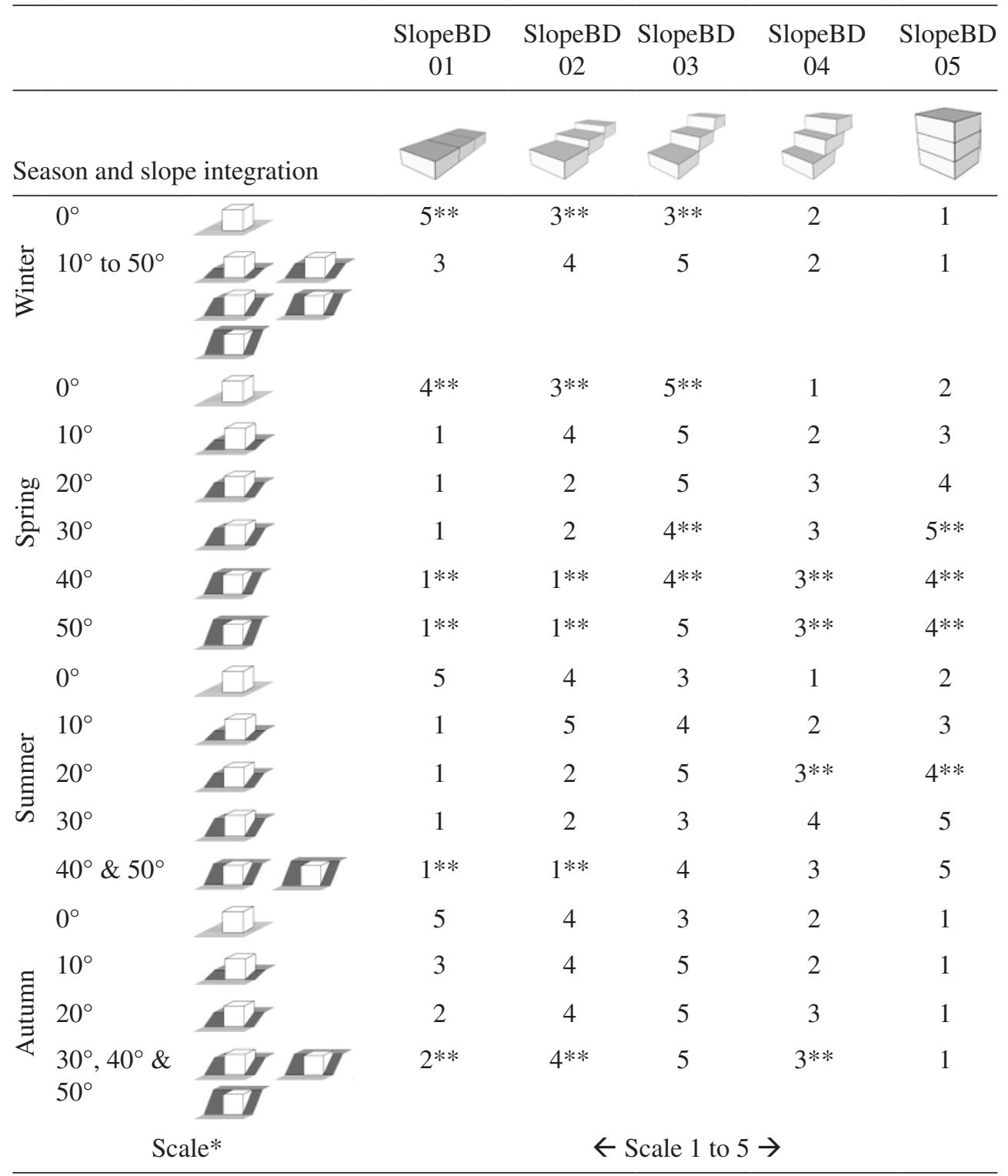

* Performance scale 1 to 5 ( 1 = Best performance $\& 5=$ Worst performance $)$; **Similar results

The complexity of the results increases when comparing all models performance alongside slope degree. Looking at Table 9, which summarises model results from best (1) to worst (5), it becomes evident that the performance of these models varies between seasons. For all slopes, the single level model without slope design (Model SlopeBD 01) has a medium performance in winter, and achieves the best results in the spring and summer with slopes from $10^{\circ}$ to $50^{\circ}$. The split level Model SlopeBD 02 also produces the best results during the spring 
and summer with slopes of $40^{\circ}$ and $50^{\circ}$. Therefore, both Model SlopeBD 01 and SlopeBD 02 can be used as part of a cooling strategy. Model SlopeBD 02 and SlopeBD 03 have poor results in winter and autumn.

The thermal performance of Model SlopeBD 04 is the most stable throughout the year. This cascade design with connected units also achieves the best results in the spring and summer for the $10^{\circ}$ slope. The performance of Model SlopeBD 05 is the most consistent throughout all seasons as it produces the lowest energy need in winter and autumn. However, its overall performance during the spring and summer is moderate. If construction costs and issues are to be taken to account, this amended section design becomes the best slope building design choice.

\section{CONCLUSIONS}

In this paper, the authors have demonstrated that slope integration can affect the thermal performance of slope construction models. For slopes between $0^{\circ}$ and $50^{\circ}$, the steeper the slope the more efficient the models' annual loads. The annual average savings can be up to $24.08 \%$ with the steepest slope. However, it was found that between $0^{\circ}$ and $30^{\circ}$ slope for each $10^{\circ}$ the average savings difference is approximately $6.5 \%$, while for slope $30^{\circ}$ to $50^{\circ}$ the results difference is small. The average savings difference is $3.2 \%$ for a $30^{\circ}$ to $40^{\circ}$ slope, and it lowers to $1.42 \%$ for a $40^{\circ}$ to $50^{\circ}$ slope. For this reason, the use of $40^{\circ}$ and $50^{\circ}$ slopes might not bring much thermal benefit. Furthermore, when looking at the results produced in all seasons, it was found that during spring, autumn, and winter and for a $30^{\circ}$ to $50^{\circ}$ slope, each model produces a distinct pattern and, again, all models produce similar results. These findings lead the authors to conclude that for this particular climate, $30^{\circ}$ is the ideal terrain angle for slope-integrated buildings.

Regarding the design effect produced by slope building designs it was found that the best design structure results come from the amended section, Model SlopeBD 05, with average annual savings of $18.54 \%$. This value indicates how relevant a slope building design can be for a building's thermal performance. The efficiency of this design is followed by the single level Model SlopeBD 01 with 15.74\%, the cascade with connected units Model SlopeBD 04 with $13.75 \%$, the split level Model SlopeBD 02 with $10.67 \%$ and lastly the cascade with independent units Model SlopeBD 03 with $0.45 \%$. It was also found that for a $0^{\circ}$ slope all models designed for slopes are more efficient than the model without slope design.

\section{REFERENCES}

[1] McHenry, P.G., Jr, Building materials and technology in arid lands. Housing in Arid Lands: Design and Planning, ed. G. Golany, The Architectural Press: London, pp. 97106, 1980.

[2] Turan, M.H., Architectural and environmental adaptation in slope settlements. Design for Arid Regions, ed. G. Golany, Van Nostrand Reinhold Company Inc.: New York, pp. 141-165, 1983.

[3] Golany, G., Subterranean settlements for arid zones. Housing in Arid Lands: Design and Planning, eds. G. Golany, The Architectural Press: London, pp. 109-122, 1980.

[4] Golany, G., Chinese Earth-sheltered Dwellings: Indigenous Lessons for Modern Urban Design, Uniersity of Hawaii Press: Honolulu, 1992.

[5] Golany, G., Urban design morphology and thermal performance. Atmospheric Environment, 30(3), pp. 455-465, 1996.

http://dx.doi.org/10.1016/1352-2310(95)00266-9 
[6] Lee, S.W. \& Shon, J.Y., The thermal environment in an earth-sheltered home Korea. Tunnelling and Underground Space Technology, 5(4), pp. 409-416, 1988. http://dx.doi.org/10.1016/0886-7798(88)90013-2

[7] Benardos, A., Athanasiadis, I. \& Katsoulakos, N., Modern earth sheltered constructions: a paradigm of green engineering. Tunnelling and Underground Space Technology, 41, pp. 46-52, 2014. http://dx.doi.org/10.1016/j.tust.2013.11.008

[8] Liu, J., Zhu, X., Yang, L. \& Hu, R., Exemplary project of green cave dwellings in Loess Plateau. Frontiers of Energy and Power Engineering in China, 4(1), pp. 122-130, 2010. http://dx.doi.org/10.1007/s11708-010-0005-1

[9] Simpson, B.J. \& Purdy, M.T., Housing on Sloping Sites: A Design Guide, Construction Press: London and New York, 1984.

[10] Hayashi, Y., The future of earth-sheltered architecture in china's farming villages. Tunnelling and Underground Space Technology, 1(2), pp. 167-169, 1986. http://dx.doi.org/10.1016/0886-7798(86)90055-6

[11] Burger, E., Geomorphic architecture: multifamily residential design solutions. Tunnelling and Underground Space Technology, 2(3), pp. 297-297, 1987. http://dx.doi.org/10.1016/0886-7798(87)90038-1

[12] Sterling, R., Carmody, J.C. \& Elnicky, G., Earth Sheltered Community Design: EnergyEfficient Residential Development, Van Nostrand Reinhold Company Limited: New York, 1981.

[13] Aughenbaugh, N.B., Subterranean settlements for arid zones. Housing in Arid Lands: Design and Planning, ed. G. Golany, The Architectural Press: London, pp. 151-158, 1980.

[14] Department of Energy, U.S., Auxiliary EnergyPlus Programs: Extra Programs for EnergyPlus, pp. 81-116, 2012, Available at: http://www.energyplus.gov

[15] Aughenbaugh, N.B., Subterranean settlements for arid zones. Housing in Arid Lands: Design and Planning, ed. G. Golany, The Architectural Press: London, pp. 151-158, 1980. 